\title{
ROLE OF PEROXIDATION AND HEME CATALYSIS IN COLORATION OF RAW MEAT
}

\author{
Alexander G. Shleikin ${ }^{1 凶}$, Yaroslav V. Medvedev² \\ ${ }^{1}$ Institute of Refrigeration and Biotechnologies, St. Petersburg National Research University of Information Technologies, \\ Mechanics and Optics, Russia \\ ${ }^{2}$ Moscow Veterinary Clinic, Russia
}

\begin{abstract}
It is known, that lipid peroxidation is one of the main factors limiting the quality and acceptability of meat and other animal tissues. The current data concerning connection of heme and peroxidation were summarized and analysed here. The muscle food compounds that are most influenced by oxidative processes include unsaturated fatty acids of lipids, amino acids of proteins and heme groups of pigments. Heme proteins and particularly myoglobin are abundant in muscle tissues. Meat colour is primarily influenced by the concentration and chemical state of heme pigments, myoglobin and hemoglobin. Oxygenated myoglobin oxidized to the brown metmyoglobin form and its accumulation is highly correlated with progress of lipid peroxidation. Heme proteins such as hemoglobin or myoglobin accelerate the decomposition of hydroperoxides to free radicals. Metmyoglobin possesses «pseudoperoxidase» activity and catalyzes the oxidation of various compounds following the reaction with hydrogen peroxide. The reaction between hydrogen peroxide and metmyoglobin results in the formation of two active hypervalent myoglobin species, perferrylmyoglobin $\left(\cdot \mathrm{MbFe} e^{\mathrm{lV}}=\mathrm{O}\right)$ and ferrylmyoglobin $\left(\mathrm{MbFe}^{\mathrm{IV}}=\mathrm{O}\right)$, which participate in lipid oxidation catalysis. Both $\mathrm{MbFe}^{\mathrm{IV}}=\mathrm{O}$ and $\bullet \mathrm{MbFe}^{\mathrm{lV}}=\mathrm{O}$ are deactivated in the presence of reducing agents, whose nature determines the overall effect of the pseudoperoxidase cycle. Hypothesis can be put forward that loss of cellular antioxidants might precede the rise of peroxidase-like activity, thus being a sign of incipient discoloration of meats and muscle components of foods.
\end{abstract}

Key words: meat colour, myoglobin, peroxidation, antioxidants

Lipid peroxidation (LPO) alongside with other processes of post mortem metabolism is decisive for quality formation of meat products. Phenomena encountered in meat raw materials as a result of LPO can be summarized under three headings: 1 - those affecting safety (formation of malonic dialdehyde, fatty acids peroxides, oxidized cholesterol etc); 2 those affecting biological value (lowering the content of non-replaceable fatty acids and vitamins, oxidative amino-acid decomposition, decrease of protein digestibility); 3 - those affecting technological quality parameters (decrease of protein solubility, colour and flavour changes, as well as appearance of a typical odour).

\section{MEAT COLOUR AND ITS NATURE}

Among the meat quality parameters affecting its salability, colour plays a special role. The colour of meat depends on the content and physical and chemical changes of hemoglobin and myoglobin $(\mathrm{Mb})-$ complex proteins of hemoprotein group contained 
in muscle tissue. Hemoproteins perform at least four main functions with respect to oxygen and energy production: 1) transportation of oxygen to tissues and its deposition, 2) catalytic oxidation of organic compounds, 3) hydrogen peroxide decomposition, 4) transfer of electrons. Myoglobin whose content in muscle tissue is responsible for up to $2 \%$ of solids, is known to play an important role in depositing oxygen delivered with blood. The amount of hemoglobin in muscle tissue of carcasses exsanguinated in a standard way is not great $(10-20 \%$ of the total pigment amount), and it is not essential in colour formation [McMillin 2010]. The main heme pigment of muscle tissue defining its colour is $\mathrm{Mb}$. The protein fraction of $\mathrm{Mb}$ molecule consists of one polypeptide chain held together firmly with 80 hydrophobic interactions and one coordinated bond with the heme. The heme represents a complex of proto-porphyrin IX with $\mathrm{Fe}^{2+}$ atom.

Four of the six bonds of Fe atom are directed at the nitrogen atoms of pyrrol rings of proto-porphyrin, the fifth one - at globin and the sixth one can be linked to a molecule of a gas - oxygen, carbon oxide etc. In all these compounds $\mathrm{Fe}$ remains bivalent $\left(\mathrm{Fe}^{2+}\right)$, however, under the action of strong oxidants and with globin denaturation, the iron of the heme becomes trivalent $\left(\mathrm{Fe}^{3+}\right)$ losing one electron. The complex compound of proto-porphyrin IX and $\mathrm{Fe}^{3+}$ is referred to as hemin or hematin. Meat colour depends on the three factors: $\mathrm{Mb}$ concentration in muscle tissue, the degree of oxygen binding with $\mathrm{Mb}$ and of the value of $\mathrm{Fe}$ charge in $\mathrm{Mb}$ heme $\left(\mathrm{Fe}^{2+}\right.$ or $\left.\mathrm{Fe}^{3+}\right)$. Oxygen bound $\mathrm{Mb}$ containing $\mathrm{Fe}^{2+}$, oxymyoglobin $\left(\mathrm{MbO}_{2}\right)$ - gives meat its bright light-red colour. Oxidized $\mathrm{Mb}$ incapable of oxygen binding - containing $\mathrm{Fe}^{3+}$ - metmyoglobin (MetMb) is of dark brown colour. Reduced $\mathrm{Mb}$ with $\mathrm{Fe}^{2+}$ ion, capable of oxygen binding produces dark red colour. It is the combination of $\mathrm{Mb}$ derivatives simultaneously present in meat that defines the meat colour. The amount of $\mathrm{Mb}$ and the state of ferroporphyrin complex in it depend on the individual characteristics of the animal (species, sex, age, stress), the meat source (muscles location. type and structure), the rate and depth of oxygen diffusion into muscle tissue, the $\mathrm{pH}$ of the medium, bacterial contamination, reduction potential, packaging, etc. [Shleikin et al. 2012, Bilska 2011, Dobrucka 2013].

\section{CORRELATION OF PEROXIDATION AND THE STATE OF HEME}

Absorption of oxygen by tissue cells during a part of post-slaughter period without its simultaneous delivery to vessels leads to reducing $\mathrm{MbO}_{2}$ content down to $15 \%$ and thus to increasing the proportion of its free form $(75 \%)$. Then, even within the first 48 hours, as aerobic exchange stops, the consumption of oxygen by the cells decreases, but the total oxygen content in the tissues increases as a result of its diffusion from the air. At the same time oxygen concentration gradient decreases from the surface to the tissue depth. Oxygen starts saturating $\mathrm{Mb}$, with important amounts of $\mathrm{MbO}_{2}$ (more than 50\%) being formed. During this period of time, the degree of restitution of the components of the reduction systems is rather high, and as such, it supports high $\mathrm{Mb}\left(\mathrm{Fe}^{2+}\right)$ content, the latter easily forming $\mathrm{MbO}_{2}$. Keeping meat at the temperature of $3.3^{\circ} \mathrm{C}$, the MetMb $\left(\mathrm{Fe}^{3+}\right)$ content in muscle tissue dramatically increases five days after storage has started. This results from depletion of reduction systems of muscle tissue, denaturation of protein molecules including NAD-dependent dehydrogenases losing Fe reduction capacity and in the end, from considerable enhancing of peroxidation $(\mathrm{PO})$ processes.

The initial bond between oxygen and heme ferrum atom is formed due to the undivided electron couple of the molecule of oxygen. This is followed by electron transfer from $\mathrm{Fe}^{2+}$ to $\mathrm{O}_{2}$, while forming trivalent ferrum with superoxide anion $\left(\mathrm{Fe}^{3+}---\mathrm{O}_{2}^{*}\right)$. Under physiological conditions heme ferrum may be recovered down to bivalent state. The principal enzyme systems involved in the process include NADH-dehydrogenase, $\mathrm{NADH}$-metmyoglobinreductase and NADH-cytochrome $b_{5}$ reductase [Dmitriev 1998]. However, these processes are much limited within meat fermentation period due to enzyme inhibition. This is accompanied by stimulation of minor ways of direct MetMb reduction by endogenous reducers (ascorbic acid, reduced glutathione, flavin, tetrahydropterin, cystein, tryptophan metabolites) and other substances.

Post-mortem change of medium $\mathrm{pH}$ and enhancing $\mathrm{PO}$ gives start to conformation of $\mathrm{MbO}_{2}$ structural failure, appearance of anions in heme area, modification of its hydrophobic characteristics leading to oxygen splitting off as anion-radical $\mathrm{O}_{2}^{--}$alongside 
with MetMb formation. Further $\mathrm{O}_{2}^{- \text {dismutation leads }}$ to formation of big quantities of $\mathrm{H}_{2} \mathrm{O}_{2}$ [Kanner et al. 1991]. A number of papers have convincingly established co-relation between PO level and coloration stability of meat raw materials [Karami et al. 2010, Luciano et al. 2009].

\section{POST-MORTEM PEROXIDATION IN ANIMAL TISSUES}

Conditions that are essential for development of peroxidation processes in biological tissues, i.e. contact with molecular oxygen and absence of intravitam defense mechanisms, are present even within initial treatment of slaughtered animals. Phospholipids of muscular fiber membranes: sarcolemma, mitochondria and sarcoplasmatic reticulum are the first to be oxidized [Morrisey et al. 1998]. Moreover, in the case of lipids kinetic duration of the process of development of free radical chain reaction is longer than that of the similar process for proteins, sugars or nucleic acids [Koppenol 1994]. Modern scientists consider lipids of biological membranes whose structure invariably possesses polyunsaturated fatty acids (PUFA) to be more sensitive to oxidation type as described above than proteins, sugars or nucleic acids [McMillin 2010].

PUFA peroxidation causes formation of toxic aldehydes of 4-hydroxy-2-alkenal, 4.5-epoxy-2-alkenal types representing stable compounds capable of diffusion into the surrounding space, causing damage to proteins and other bio-molecules [Gardner 1989]. LPO is known to be accompanied by increase of water content in cell membrane, the latter causing lipids to change to liquid-crystal state. Phase change of membrane lipids due to their peroxidation leads to conformation change of membrane proteins and thus, to the change in membrane permeability, ion channels functions, as well as to derangement of functions of enzymatic systems as a whole [Dmitriev 1998]. Proteins are capable of catching 50 to $75 \%$ of free-radical compounds formed. It is sulfur-containing (methionine, cysteine) and aromatic (histidine, tryptophan, tyrosine and phenylalanine) amino-acid residues of proteins that are the most sensitive for oxidation [Niki et al. 1992]. Oxidative modification mechanisms of proteins affect both radicals of amino-acid residues and polypeptide structure of protein. They include: 1) carbohydrate radicals located within the depth of protein molecule, 2) peroxi-radicals, 3) alcoxi-radicals, 4) thiyl radicals, nitrogenous radicals, 5) aromatic radicals of amino-acid residues. Formation of radical centers brings about the change in spatial structure of protein molecules, increase of hydrophobic properties, inactivation of an important group of enzymes and membrane permeability disruption [Gebicki 1997].

A group of structurally quite unusual dipeptides including carnosine ( $\beta$-alanil-L-histidine), homocarnosine $(\gamma$-amino-butiril-L-histidine) and anserine ( $\beta$-alanil-1-metyl-L-histidine) is regarded as prospective antioxidant molecules acting basically in muscular tissues [Tiulina et al. 2002]. Experimental data show that the antioxidant effect of these endogenous substances is likely to be provided by histidine residue. In fact, in its free state this amino-acid is a HO-radical catcher and one of the most effective "suppressors" of singlet oxygen.

The proportion of free histidine in biological material is negligible (except for fish muscular tissue) for it to perform antioxidant function in vivo, however, when included in these peptides, its concentration can achieve as high as millimoles level (up to $40 \mathrm{mM}$ of carnosine in mammal muscles). Moreover, suppression of singlet oxygen by histidine within carnosine appeared to be three times as effective as the similar activity of free amino-acid or of a mixture of free histidine and $\beta$-alanine [Tiulina et al. 2002]. Oxo-ferrilic group $\mathrm{Fe}^{4+}=\mathrm{O}$ takes part in the catalysis within the active centre of peroxidases. This may explain the high oxidative capacity of such enzymes $(\mathrm{E} \geq+1.0 \mathrm{~V})$ playing a crucial part both in leukocyte destroying microorganisms and on biosphere level - in lignin decomposition by enzymes [Kanner et al. 1991]. Similar processes also seem to take place in active centers of enzymes using molecular oxygen for provision of oxidase and oxygenase reactions in living systems. During these reactions toxic intermediates of oxygen reduction are not released to surrounding space but undergo transition down to the final products of $\mathrm{H}_{2} \mathrm{O}_{2}$ and $\mathrm{H}_{2} \mathrm{O}$. There are a number of papers dealing with the specific functioning of reduction enzymes during post-mortem period. Thus, an investigation of microsomal fractions of skeletal muscles of chicken and fish has shown the presence of enzymatic 
systems catalysing microsomal lipids oxidation within the presence of co-factors. The similar systems have been discovered post mortem in the muscles of cattle [Rhee et al. 1985].

Enzymatic lipid PO in meat microsomes requires the presence of NAD or NADP as well as of ADP and $\mathrm{Fe}^{2+}$ or $\mathrm{Fe}^{3+}$ for maximizing reaction rate. Apart from microsomal oxidoreductases, mitochondrial systems of enzymatic oxidation may function in raw meat [Luo and Hultin 1986]. Thus, the data proves that animal meat possesses enzymatic systems capable of catalyzing lipid oxidation, and the regularities of catalytic mechanisms functioning are close to NADP-dependent enzymatic oxidation of biological membranes in model systems [Oertling et al. 1990].

\section{HEMEPROTEINS AS ACTIVATORS OF KINETICALLY "INERT" HYDROPEROXIDES}

Hemeproteins can be classified into three groups according to their reactions in hydroperoxide systems: $\mathrm{Mb}$ and hemoglobin initiate radicals of hydroperoxides and are involved in single electron oxidation of substrates; peroxidase and catalase form I and II complexes reacting according to single electron mechanism and P-450 have a double action: they generate I and II complexes as well as $\mathrm{HO}^{\circ}, \mathrm{RO}^{\circ}$ and $\mathrm{RO}_{2} \cdot$ radicals [Metelitza and Karasyova 2007]. The theory of heme peroxidation catalysis started with catalytic effect of hemeproteins on oxidation of polyunsaturated fatty acids described by M.E. Robinson. A.L. Tappel suggested the presence within a product of certain initial quantities of peroxides reacting either with bivalent or with trivalent heme ferrum and thus undergoing hemolytic decomposition leading to the formation of alcoxi- and peroxiradical respectively. These radicals initiate creation of further chains. It was also shown that within the process of heme catalysis of lipid oxidation there is a period of induction essential for generating a certain quantity of hydroperoxides.

$\mathrm{Mb}$ is currently regarded as the main catalyst of peroxidation in meat raw materials. MetMb possesses «pseudoperoxidase» activity and catalyzes the oxidation of various compounds following the reaction with hydrogen peroxide by scheme on Figure 1.

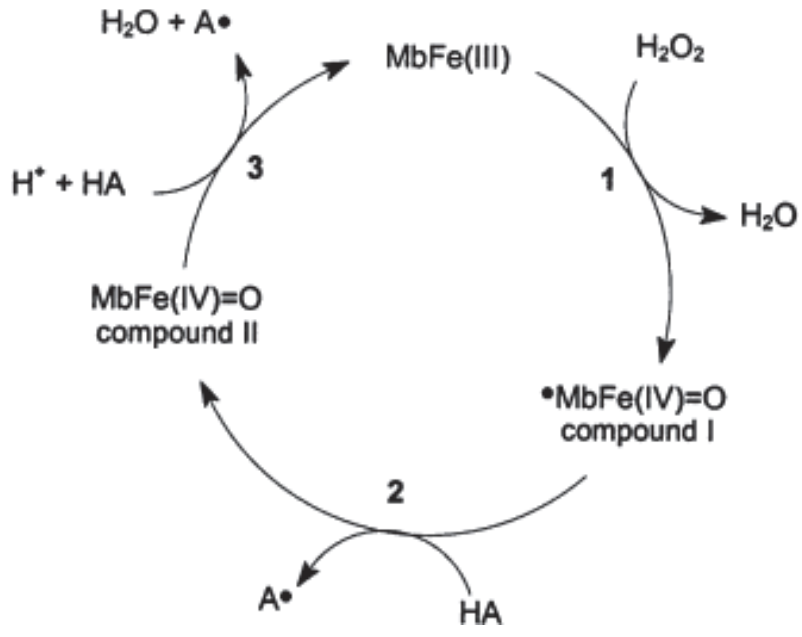

Fig. 1. Peroxidase cycle of Mb [Carlsen at al. 2003]

Interaction between hydroperoxides and MetMb forming hydroperoxide metallic complexes results in considerable enhancing of active oxygen forms generation [Chan et al. 1997]. The presence and properties of such complexes for peroxidases and catalases in tissues have been proved. Experiments have been conducted studying the possibility of initiating oxidative processes in muscle fiber membranes by MetMb activated by hydrogen peroxide [Kanner et al. 1991]. As a result, the following sequence of oxidative reactions in muscles has been suggested: self-oxidative and oxidative process of $\mathrm{MbO}_{2}$ transformation into MetMb and hydrogen peroxide, hydrogen peroxide activation of MetMb to porphyrilcation-radical containing tetravalent ferrum, porphyrilcation-radical initiating lipid oxidation. Model systems with glucoseoxidase have shown that continuously fed minor quantities of $\mathrm{H}_{2} \mathrm{O}_{2}$ activate MetMb and enhance LPO processes stronger that with metmyoglobin incubation with larger quantities of $\mathrm{H}_{2} \mathrm{O}_{2}$.

Much of the peroxide is produced in meat tissues as a result of non-enzymatic reactions such as that of $\mathrm{MbO}_{2}$ self-oxidation to MetMb resulting in hydrogen peroxide forming via a number of intermediate compounds [Kanner et al. 1991]. As $\mathrm{MbO}_{2}$ transition to MetMb is a phenomenon typical for the processes of meat treatment and storage, it would be logical to suggest that $\mathrm{H}_{2} \mathrm{O}_{2}$ may be produced in meat in amounts sufficient for MetMb activation. 


\section{REFERENCES}

Bilska A., 2011. Packaging systems for animal origin food. Logforum 7, 1, 4 .

Dmitriev L.F., 1998. Cytochrome b5 and tocopherol provide functions of lipid-radical cycles and energy conversion in membranes. Biochemistry 63 (10), 1447-1450 [in Russian].

Carlsen C.U., Skovgaard I.M., Skibsted L.H., 2003. Pseudoperoxidase activity of myoglobin: kinetics and mechanism of the peroxidase cycle of myoglobin with $\mathrm{H}_{2} \mathrm{O}_{2}$ and 2,2-azino-bis(3-ethylbenzthiazoline-6-sulfonate) as substrates. 2003. J. Agric. Food Chem. 51. 5815-5823.

Chan W.K.M., Faustman C., Yin M., Decker E.A., 1997. Lipid oxidation induced by oxymyoglobin and metmyoglobin with involvement of $\mathrm{H}_{2} \mathrm{O}_{2}$ and superoxide anion. Meat Sci. 46, 181-190.

Dahl T.A., Midden W.E., Hartman P.R., 1988. Same prevalent biomolecules as defences against singlet oxygen. J. Photochem. Photobiol. 43, 357-362.

Dobrucka R., 2013. Future of active and intelligent packaging industry. Logforum 9 (2), 103-110.

Gardner H.W., 1989. Oxygen radical chemistry of polyunsaturated fatty acid. Free Radic. Biol. Med. 7, 65-86.

Gebicki J.M., 1997. Protein hydroperoxides as new reactive oxygen species. Redox Rep. 3, 99-110.

Han D., McMillin K.W., Godber J.S., 1994. Hemoglobin, myoglobin, and total pigments in beef and chicken muscles: chromatographic determination. Food Sci. 59, 1279-1282.

Kanner J., Salan M.A., Harel S., Shegalovich I., 1991. Lipid peroxidation of muscle food: The role of cytozolic fraction. J. Agric. Food Chem. 39, 242-246.

Karami M., Alimon A.R., Sazili A.Q., Goh Y.M. 2010. Meat quality and lipid oxidation of infraspinatus muscle and blood plasma of goats under dietary supplementation of herbal antioxidants. J. Anim. Vet. Adv. 9 (24), 3039-3047.

Koppenol W.H., 1994. Chemistry of iron and copper in radical reactions. In: Free radical damage and its control.
Ed. C.A. Rise-Evans, R.H. Burdon. Elsevier Amsterdam, 3-24.

Luciano G., Monahan F.J., Vasta V., Pennisi P., Bella M., Priolo A., 2009. Lipid and color stability of meat from lambs fed fresh herbage or concentrate. Meat Sci. 82 (2), 193-199.

Luo S.W., Hultin H.O., 1986. An enzymic-catalyzed lipid oxidation system in troutmuscle mitochondria. 46th Annual Meeting of the Institute of Food Technologists. Dallas, Texas, 15-18 June, 1986.

McMillin K.W., 2010. Meat production and quality. In: Goat science and production. Ed. S. Solaiman. Wiley-Blackwell Publ., 255-273.

Metelitza D.I., Karasyova E.I., 2007. Initiation and inhibition of free-radical processes in biochemical peroxidase systems: A review. Appl. Biochem. Microbiol. 43 (5), 537-564 [in Russian].

Morrisey P.A., Sheehy P.J.A., Galvin K., Kerry J.P., 1998. Lipid stability in meat and meat products. Meat Sci. 49, 73-86.

Niki E., Noguchi N., Gotoh N., 1992. Dynamics of lipid peroxidation and its inhibition by antioxidants. J. Biochem. Soc. Trans. 21, 313-317.

Oertling W.A., Hoogland H., Babcock G.T., Wever R., 1990. Identification and properties of an oxoferryl structure in myeloperoxidase compound II. J. Biochem. 29 (15), 5395-5400.

Rhee K.S., Dutson T.R., Savell J.W., 1985. Enzymic lipid peroxidation in beef muscle microsomes as affected electrical stimulation and postmortem muscle excision time. J. Food. Biochem. 9, 27-36.

Shleikin A.G., Medvedev Y.V., Shatalov I.S., 2012. Effect of ascorbic acid on the peroxidase activity of muscle tissue. J. Proc. Appar. Pisch. Proizvod. 2, [online], http:// processes.open-mechanics.com/ [in Russian].

Tiulina O.V., Bychkova O.N., Prokopieva V.D., Boldyrev A.A., 2002. Histidincontaining dipeptides and blood cells. Probl. Gemat. 4, 53-63 [in Russian].

Accepted for print - Zaakceptowano do druku: 11.10.2013 